\title{
Immunosuppressant Therapy Adherence after Kidney Transplantation
}

\author{
Ahmet Karaman $^{1^{*}}$ (D), Yasemin Özhanli ${ }^{\text {(D) Ezgi Seyhan-Ak }}{ }^{3}$ (D), Seher Deniz Öztekin ${ }^{3}$ (D), \\ Ertuğrul Göksoy ${ }^{4}$ (D), Nurhan Seyahi ${ }^{5}$ (iD and Emel Şengül' ${ }^{6}$ (iD)
}

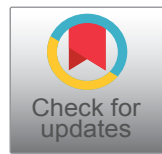

${ }^{1}$ Surgical Nursing Department, Faculty of Nursing, Mersin University, Mersin, Turkey

${ }^{2}$ Surgical Nursing Department, Division of Nursing, Faculty of Health Sciences, Kocaeli University, Kocaeli, Turkey

${ }^{3}$ Surgical Nursing Department, Florence Nightingale Faculty of Nursing, Istanbul University-Cerrahpaşa, Istanbul, Turkey

${ }^{4}$ Department of General Surgery, Retired Faculty Member, Cerrahpaşa Faculty of Medicine, Istanbul University-Cerrahpaşa, istanbul, Turkey

${ }^{5}$ Department of Internal Medicine, Division of Nephrology, Cerrahpaşa Faculty of Medicine, Istanbul University-Cerrahpaşa, Istanbul, Turkey

${ }^{6}$ Cerrahpaşa Faculty of Medicine Hospital, Istanbul University-Cerrahpaşa, İstanbul, Turkey

*Corresponding author: Ahmet Karaman, PhD, MSc, RN, Surgical Nursing Department, Faculty of Nursing, Mersin University, Çiftlikköy Campus, 33343, Yenişehir, Mersin, Turkey, Fax: 0324-361-05-71, Tel: 0324-361-00-01/14237

\begin{abstract}
Background: Immunosuppressive therapy (IST) is administered to the individual to prolong the graft survival; thus, the survival of the patient after organ transplantation. Adherence of the individual to IST is crucial.

Aim: In this study, it was aimed to find out patients' adherence to immunosuppressant therapy after kidney transplantation.

Material and Methods: The sample of this descriptive study consisted of 50 patients; who underwent kidney transplantation in a university hospital in Istanbul and who applied to the hospital for follow-up in the period between May 2017 and September 2017. Data were collected using the "Descriptive Characteristics Information Form" and the "Immunosuppressant Therapy Adherence Scale".

Results: All of the participants in the study achieved the targeted blood levels of immunosuppressants and $54 \%$ had never forgotten/postponed taking the immunosuppressants. The patients; who forgot/postponed taking prescribed medications, reported the associated reasons as follows: Forgetfulness/carelessness $(16 \%)$, leaving the medications at home forgetfully $(14 \%)$, unable to take medications because of being away from home (10\%), and barriers related to their occupation $(6 \%)$. The mean score of the Immunosuppressant
\end{abstract}

Therapy Adherence Scale was $11.40 \pm 0.75$ and individuals with a post-transplant period of shorter than two years had a higher mean score $(11.81 \pm 0.40)$ of the scale in this study $(p<0.05)$.

Conclusions: In the study, immunosuppressant therapy adherence of patients was found high and all patients achieved the targeted blood levels of immunosuppressants after kidney transplantation.

\section{Keywords}

Adherence to treatment, Immunosuppressive therapy, Organ transplantation

\section{Introduction}

Kidneys are the most commonly transplanted organ in the world and Turkey. Dialysis methods are several but allow for replacing only a minor proportion of the total glomerular filtration function of a healthy kidney. Other renal functions; including the production of erythropoietin, activation of vitamin $D$, and the maintenance of the acid-base balance cannot be replaced at all. Therefore, kidney transplantation is the most appropriate treatment method for end-stage renal failure as a life-saving and cost-effective treatment modality [1,2].

Citation: Karaman A, Özhanli Y, Seyhan-Ak E, Öztekin SD, Göksoy E, et al. (2021) Immunosuppressant Therapy Adherence after Kidney Transplantation. Int Arch Nurs Health Care 7:157. doi. org/10.23937/2469-5823/1510157

Accepted: April 19, 2021: Published: April 21, 2021

Copyright: (c) 2021 Karaman A et al. This is an open-access article distributed under the terms of the Creative Commons Attribution License, which permits unrestricted use, distribution, and reproduction in any medium, provided the original author and source are credited. 
Immunosuppressive therapy (IST) is administered to the individual to prolong the graft survival; thus, the survival of the patient after organ transplantation. Adherence of the individual to IST is crucial [2]. Medication non-adherence of organ transplant patients is described as medication errors/skipping at least one dose of the medication in a month or taking the drug two-and-ahalf hours later than the prescribed time at least once in a month [3].

The rates of immunosuppressant therapy adherence after organ transplantation vary from $15 \%$ to $68 \%$ [4-6]. Age, gender, the time elapsed after organ transplantation, working status of the individual, cost of immunosuppressants, drug side effects, number of drugs taken in a day, frequent updates to the IST regimen, psychological problems, and disbelief in treatment are reported as factors affecting IST adherence $[1,6,7]$.

In a study conducted by Chisholm, et al. [5] on kidney transplant patients in the United States of America (USA), $65 \%$ of the patients were found adherent to IST. The adherent patients were younger; they underwent organ transplantation more recently, and achieved the targeted serum levels of immunosuppressants. Another study by Russel, et al. [2] reported that $86 \%$ of the kidney transplant patients included in the study were non-adherent to IST. Gorevski, et al. [8] found out that non-adherence in liver transplant recipients was associated with young age, whereas non-adherence in kidney transplant recipients was associated with depression, decreased physical functioning, and personality traits. In the study conducted by Cheng, et al. [9] on 412 kidney transplant recipients, it was reported that the patients had complaints about the medications used for IST and frequently complained of memory impairment, which acted on IST adherence unfavourably. Madran, et al. [6], reported that IST adherence was higher in women and in individuals with a post-transplant period of shorter than two years.

One of the major factors acting on graft survival, prevention of transplant rejection, and the achievement of low mortality and morbidity rates after organ transplantation is the training of transplant patients about IST adherence in the post-transplantation period. However, most patients fail to achieve full adherence to IST. For this reason; it is critical that organ transplant nurses should determine the level of IST adherence of individuals after transplantation, identify positive and negative factors that act on adherence, and implement the necessary care interventions. Despite the availability of studies in the international scientific literature that investigate adherence to IST after kidney and liver transplantation [7-9], only a few studies have been conducted in Turkey $[6,7,10]$. In this context, the study was planned and conducted to determine adherence levels of individuals; who underwent kidney transplantation, and to identify factors that act on adherence to IST.

\section{Methods}

\section{Study design}

This study was carried out descriptively.

\section{Study population and sample}

The population of the study consisted of all patients, who underwent kidney transplantation in a University Hospital in Istanbul. The study sample consisted of 50 patients; who applied to the same centre for post-transplant follow-up in the period between May 2017 and September 2017 and who met the sample selection criteria of the study. A target sample size was set aiming to include a number of patients 10 times as much as the number of the items in the scale ( 40 patients). The research was stopped after including 50 patients.

The inclusion criteria of the study were as follows: Undergoing organ transplantation in the centre, where the study was conducted; a period of at least 3 months elapsing after the hospital discharge of the individual after organ transplantation, being 18-years-old or older, using immunosuppressants, being able to take medications on their own, not having medically confirmed cognitive and mental impairments, being able to speak Turkish, and voluntarily agreeing to participate in the research.

\section{Data collection tools and collection of the data}

Data were collected using the "Descriptive Characteristics Information Form" and the "Immunosuppressive Therapy Adherence Scale (ITAS)".

Descriptive Characteristics Information Form: This form comprised 9 items to collect information about patients participating in the study including age, gender, educational status, working status after organ transplantation, the time elapsed after organ transplantation, donor type, the number of drugs used in a day, the achievement of the targeted immunosuppressant levels in the blood, and the organ rejection history.

Immunosuppressive Therapy Adherence Scale (ITAS): ITAS was developed by Morisky, et al. (1986) to evaluate the adherence of hypertensive patients to antihypertensive drugs. Chisholm, et al. [5] adapted the scale for use in organ transplant patients in order to evaluate adherence to IST. The reliability and validity study of the scale in Turkish was conducted by Madran, et al. [6]. The scale comprises four items that question the adherence of patients to IST in the last three months after organ transplantation. The items are scored on a four-point Likert scale. The answers given to the scale questions are scored to assess adherence to IST as follows: Three points for response values of $0 \%$, two points for $0-20 \%$, one point for $21-50 \%$, and zero points for values of more than $>50 \%$. The lowest and highest scores that can be obtained from the scale are zero and 12 , respectively. Increasing scale scores indicate higher ad- 
herence to IST. After determining the percentage points correctly conforming to the responses provided by the patients, the suitable options are selected and the total scale score of the patient is calculated. The scale was designed in a way to reflect the degree of patient adherence in percentage points because it was considered that short expressions such as "yes" and "no" answers would limit determining the extent of IST adherence comprehensively. The Cronbach's alpha reliability coefficient of the scale is 0.65 . In this study, the Cronbach alpha coefficient of the scale was found to be 0.80 .

After obtaining verbal and written informed consent from the individuals, descriptive characteristics were collected by the face-to-face interview method on the days of outpatient clinic services at the study site. ITAS was filled by patients.

Blood levels of immunosuppressants were not specifically controlled for the study. The patients' blood levels of immunosuppressants, which were tested once a month, were checked for the previous three months.

\section{Data analysis}

The study data were analyzed statistically by the IBM SPSS 22.0 (IBM Statistical Package for Social Sciences Corp.; Armonk NY, USA, 2013) software package. Besides the descriptive statistical methods (mean, standard deviation, and frequencies), non-normally distributed data were analyzed by the Mann-Whitney test between paired groups and the Kruskal Wallis Test across multiple groups. The linear relationship between age and scale scores was evaluated using the Pearson correlation test. The level of significance was assessed at a $p$-value of $<0.05$.

\section{Ethical considerations}

Before starting the study, the permission to use the scale was obtained via e-mail correspondence with Madran, et al. [6], who performed the validity and reliability study of the scale in Turkish. The approval of the Clinical Studies Ethics Committee (decision number A-53 dated 06/06/2017); the written permission from the hospital, where the study data were collected, and the written and verbal consent of the individuals included in the study sample were obtained before commencing the study.

\section{Results}

The mean age was $43.24 \pm 13.92$ years in the sample group; which consisted of women at a rate of $50 \%$ and primary school graduates at a rate of $44 \%$. Of the participants; $64 \%$ did not work actively after the kidney transplant, $78 \%$ had a post-transplant period of longer than 2 years, $72 \%$ received a kidney transplant from a living donor, $48 \%$ took $6-10$ pills in a day, $42 \%$ took two immunosuppressive medications in a day, all patients achieved the targeted immunosuppressant blood levels, and no patients had a history of transplant rejection (Table 1).
Table 1: Demographic characteristics of transplantation patients $(n=50)$.

\begin{tabular}{|l|l|}
\hline Demographic Characteristics & Mean \pm SD \\
\hline Age & $43.24 \pm 13.92$ \\
\hline & $\mathbf{n}(\%)$ \\
\hline Gender & $25(50.0)$ \\
\hline Male & $25(50.0)$ \\
\hline Female & \\
\hline Educational status & $6(12.0)$ \\
\hline Literated & $22(44.0)$ \\
\hline Primary school & $14(28.0)$ \\
\hline High school & $8(16.0)$ \\
\hline Undergraduate and above & $18(36.0)$ \\
\hline Working status after organ transplantation \\
\hline Yes & $32(64.0)$ \\
\hline No & \\
\hline The time elapsed after organ transplantation &
\end{tabular}

The time elapsed after organ transplantation

\begin{tabular}{|l|l|}
\hline Less than 2 years & $11(22.0)$ \\
\hline More than 2 years & $39(78.0)$ \\
\hline Donor type & \\
\hline Living donor & $36(72.0)$ \\
\hline Cadaveric donor & $14(28.0)$ \\
\hline Number of drugs taken in a day & $23(46.0)$ \\
\hline $1-5$ pieces & $24(48.0)$ \\
\hline $6-10$ pieces & $3(6.0)$ \\
\hline 10 pieces and above & \\
\hline
\end{tabular}

The achievement of the targeted immunosuppressant levels in the blood

\begin{tabular}{|l|l|}
\hline Yes & $50(100.0)$ \\
\hline No & $0(0.00)$ \\
\hline Rejection history & \\
\hline Yes & $0(0.00)$ \\
\hline No & $50(100.0)$ \\
\hline Total & $50(100.0)$ \\
\hline
\end{tabular}

SD: Standard deviation.

In this study, the mean ITAS score was $11.40 \pm$ 0.75 . The mean ITAS score was higher in patients with a post-transplant period of shorter than two years ( $p$ $<0.05$ ). There were no differences in the mean ITAS scores by the variables of gender, working status after transplantation, donor types, and the total number of pills taken in a day $(p>0.05)$. It was determined that there was not a relationship between age and the mean ITAS score $(r=0.229 ; p>0.05)$ (Table 2$)$.

Of the sample group; $54 \%$ had never forgotten/ postponed taking the prescribed immunosuppressants. The participants; who forgot/postponed taking the prescribed immunosuppressants reported the following reasons as follows: Forgetfulness/carelessness (16\%), forgetfully leaving the medications at home (14\%), being away from home (10\%), and work-related barriers (6\%) (Table 3). 
Table 2: Comparison of the demographic characteristics and the mean score of the Immunosuppressive Therapy Adherence Scale.

\begin{tabular}{|c|c|c|c|c|c|}
\hline $\begin{array}{l}\text { Demographic } \\
\text { characteristics }\end{array}$ & $\begin{array}{l}\text { The mean ITAS } \\
\text { score }\end{array}$ & SD & Min. & Max. & $\mathbf{p}$ \\
\hline Age & 11.40 & 0.76 & 9 & 12 & $\begin{array}{l}0.109^{*} \\
r=0.229\end{array}$ \\
\hline \multicolumn{6}{|l|}{ Gender } \\
\hline Female & 11.52 & 0.65 & 10 & 12 & \multirow[t]{2}{*}{$0.324^{* *}$} \\
\hline Male & 11.28 & 0.84 & 9 & 12 & \\
\hline \multicolumn{6}{|c|}{ The time elapsed after organ transplantation } \\
\hline Less than 2 years & 11.82 & 0.40 & 11 & 12 & \multirow[t]{2}{*}{$0.031^{\star \star}$} \\
\hline More than 2 years & 11.28 & 0.79 & 9 & 12 & \\
\hline \multicolumn{6}{|c|}{ Working status after organ transplantation } \\
\hline Yes & 11.22 & 0.88 & 9 & 12 & \multirow[t]{2}{*}{$0.269^{* *}$} \\
\hline No & 11.50 & 0.67 & 10 & 12 & \\
\hline \multicolumn{6}{|l|}{ Donor type } \\
\hline Living donor & 11.28 & 0.81 & 9 & 12 & \multirow[t]{2}{*}{$0.078^{* *}$} \\
\hline Cadaveric donor & 11.71 & 0.47 & 11 & 12 & \\
\hline \multicolumn{6}{|c|}{ Number of drugs taken in a day } \\
\hline 1-5 pieces & 11.22 & 0.90 & 9 & 12 & \multirow[t]{3}{*}{$0.192^{* \star *}$} \\
\hline 6-10 pieces & 11.50 & 0.59 & 10 & 12 & \\
\hline 10 pieces and above & 12.00 & 0.0 & 12 & 12 & \\
\hline
\end{tabular}

Table 3: Reasons of forgotten/postponed taking immunosuppressants $(n=50)$.

\begin{tabular}{|l|l|}
\hline Reasons of forgotten/postponed & $\mathbf{n ~ ( \% )}$ \\
\hline Forgetfulness/carelessness & $8(16.0$ \\
\hline Forgetfully leaving the medications at home & $7(14.0)$ \\
\hline Being away from home & $5(10.0)$ \\
\hline Work-related barriers & $3(6.0)$ \\
\hline Never forgotten/postponed & $27(54.0)$ \\
\hline
\end{tabular}

\section{Discussion}

Adherence to IST after kidney transplantation is crucial to preserve graft functions and prevent transplant rejection [11]. Acute rejection has been reported to be related to non-adherence to IST approximately in 50\% of acute rejection reactions and approximately in $15 \%$ of organ losses in the late post-transplant period in kidney transplant patients $[7,11]$. Therefore, adherence to IST is expected and aimed after organ transplantation. The rate of non-adherence to IST in kidney transplant patients is reported to vary from $15 \%$ to $55 \%$ in the literature [1]. Dew, et al. [12] reported the rate of IST non-adherence was as $36 \%$ in kidney transplant patients. In the studies conducted by Ichimaru, et al. [13] and Germani, et al. [14] they were reported that the rate of non-adherence to treatment was high in kidney transplant patients. Contrary to the results of that study, Şahin [10], Weng, et al. [15], Promraj, et al. [16], Albekairy, et al. [17], found high adherence to IST in the majority of pa- tients after organ transplantation. Consistent with the information in the literature $[10,15,16]$, it was found in this study that patients' adherence to IST was high.

Studies in the literature $[18,19]$ report that young individuals have lower IST adherence compared to adults because individuals in younger age groups go to bed late, get out of the bed late, drink alcohol, have an active social life, and disregard treatment assuming that they would never be sick. The high IST adherence found in this study may be explained by the fact that most of the patients included in the study were adults.

In the literature, factors associated with non-adherence to IST after organ transplantation were reported as problems related to young age, the time elapsed after transplantation, black race, daily routines, characteristics and doses of medications, medication costs, and access to medications $[11,15,20]$.

The rate of non-adherence to IST is reported to be high in young people because of reasons including the concerns about the body image, the level of cognitive development (the extent of abstract thinking and behaviour control), being in active professional life, and difficulties in adjusting to daily routines due to the lifestyle $[18,21,22]$. It is reported that the second most non-adherent group are old people after young individuals and it is suggested that forgetfulness plays a major role in the development of non-adherence [18]. Similar to the study conducted by Albekairy, et al. [17], 
Muduma, et al. [18] identified old age as a factor acting on IST adherence unfavourably in their study on liver transplant patients. In the studies conducted by Şahin, et al. [10] and Burn, et al. [23], it was found out that adherence to IST increased with progressing age. In the study conducted by Ören and Sucu-Dağ [7], it was found out that individuals under the age of 40 had lower IST adherence. In the study conducted by Özdemir and Talas [20], it was reported that most patients were in the adult age group and that there was not a relationship between age and IST adherence. In this study, it was observed that there was not a relationship between age and the IST adherence rates consistent with the information in the literature [20].

Although it is reported that the socioeconomic factors involved in adherence mainly include education levels, profession, and income levels; the World Health Organization (WHO) consider that gender, age, ethnic origins, and the availability of social support are also included in the group of socioeconomic factors within the context of medication adherence [1,2]. Denhaerynck, et al. [4] and Griva, et al. [21] reported that non-adherence to IST was more common in men in their study. Gheith, et al. [24] showed that the risk of non-adherence to IST was higher in female organ transplant patients. In this study; consistent to the results reported by Butler, et al. [3] and Russell, et al. [25], no differences were found in IST adherence rates by gender.

Another factor associated with non-adherence to IST after organ transplantation is the time elapsed after transplantation. It has been reported that adherence to IST progressively decreased each following year after kidney transplantation [15]. Hamedan, et al. [20] evaluated IST adherence in their study and reported that the highest rate of adherence occurred in the first post-transplant year and the lowest adherence rate occurred beyond the $16-21$ years post-transplant. Similarly, Burkhalter, et al. [26] reported that non-adherence to IST increased as the time elapsed got longer after transplantation. Özdemir and Talas [20] reported in their study that adherence to IST increased as the time elapsed after transplantation got longer. Similar to the results reported by the studies conducted by Hamedan, et al. [20] and Burkhalter, et al. [26], it was found in this study that the patients with post-transplant periods of shorter than two years had high IST adherence. The patients' adherence to IST might result from their fear of potential transplant rejection in the early post-transplantation period as they had just been freed of dialysis.

It is reported that the number of medications required to be taken daily by the individual is one of the factors affecting adherence to IST $[1,15]$. In the study conducted by Weng, et al. [15], it was found out that medication adherence increased as the number of medications to be taken in a day by kidney transplant patients was reduced. Moralesa, et al. [27] found the medication adherence was very high in kidney transplant patients. In this study, no differences were found in IST adherence by the number of medications to be taken in a day.

In individuals who continue to work actively after organ transplantation, the intensity of working life is considered as one of the factors that act on medication adherence unfavourably $[6,7]$. In this study, no differences were found in IST adherence between the participants, who were employed, and the ones, who stopped working after organ transplantation. The findings of the study; which showed that neither the employment status nor the number of medications to be taken in a day acted on IST adherence after transplantation, might have resulted from the use of smartphone applications, electronic reminders, and tracking systems commonly utilized today as aids for remembering to take prescribed medications.

Adherence to drug therapy is defined as taking the correct doses of the prescribed medication regularly at proper time intervals [1]. It is important to take immunosuppressants at the right time of the day in order to maintain graft functions and prevent transplant rejection. Forgetfulness is a major factor acting on adherence to IST [15]. It has been shown in the scientific and academic literature that the major cause of non-adherence to IST is forgetting to take medications $[1,15]$. In this study, it was found that the majority of the patients did not forget/postpone taking the prescribed medications. The participants of this study; who forgot/postponed taking the prescribed medication claimed forgetfulness as the cause consistent with the literature. The results of this research are considered important as it provides grounds for the implementation of interventions that would remind individuals to take the prescribed medication.

\section{Limitations of Study}

This study has small sample size and a single-center design which precludes the generalization of the results to the overall organ transplantations patients.

\section{Conclusion and Recommendations}

In the study, adherence to IST was found high and all patients achieved the targeted blood levels of immunosuppressants after kidney transplantation. It may be suggested that the causes of forgetfulness specifically at the individual level should be identified and nursing interventions should be applied at the root-cause level when non-adherence is detected. It may also be suggested that further studies on larger sample groups should be conducted.

\section{References}

1. Tuncer M, Khorshtd L (2018) Böbrek nakli hastalarında immünosüpresan tedaviye uyum ve hemşirenin sorumluluklari. Nefroloji Hemşireliği Dergisi 13: 26-31. 
2. Russell CL, Cetingok M, Hamburger KQ, Owens S, Thompson D, et al. (2010) Medication adherence in older renal transplant recipients. Clin Nurs Res 19: 95-112.

3. Butler JA, Roderick P, Mullee M, Mason JC, Peveler RC (2004) Frequency and impact of nonadherence to immunosuppressants after renal transplantation: A systematic review. Transplantation 77: 769-776.

4. Denhaerynck K, Burkhalter F, Schäfer-Keller P, Steiger J, Bock A, et al. (2009) Clinical consequences of non adherence to immunosuppressive medication in kidney transplant patients. Transpl Int 22: 441-446.

5. Chisholm MA, Lance CE, Williamson GM, Mulloy LL (2005) Development and validation of the immunosuppressant therapy adherence instrument (ITAS). Patient Educ Couns 59: 13-20.

6. Madran B, Karayurt Ö, Spivey CA, Chisholm-Burns MA (2016) Immunosuppressant therapy adherence scale for transplant recipients: The study of validity and reliability. Turkiye Klinikleri Journal of Nursing Sciences 8: 325334.

7. Ören E, Sucu Dağ G (2020) Kuzey Kibris Türk Cumhuriyeti'nde böbrek nakli yapilmiş hastalarin immunsupresif tedaviye uyum düzeylerinin belirlenmesi. Journal of Education and Research in Nursing 17: 1-9.

8. Gorevski E, Succo, P, Sachdeva J, Cavanaugh TM, Volek $P$, et al. (2013) Is there an association between immunosuppressant therapy medication adherence and depression, quality of life, and personality traits in the kidney and liver transplant population? Patient Prefer Adherence 7: 301-307.

9. Cheng CY, Lin BY, Chang KH, Shu KH, Wu MJ (2012) Awareness of memory impairment increases the adherence to immunosuppressants in kidney transplant recipients. Transplant Proc 44: 746-748.

10. Şahin N (2016) Karaciğer ve böbrek transplantasyonu sonrası immunosupresiftedaviye uyum ve etkileyen faktörler. Dokuz Eylül Üniversitesi Sağlık Bilimleri Enstitüsü, İzmir.

11. Güzel H, Korkmaz M (2019) Life quality and compliance after transplant: The case of Turkey. Transplant Proc 51: 1029-1037.

12. Dew MA, DiMartini AF, Dabbs ADV, Myaskovsky L, Steel $\mathrm{J}$, et al. (2007) Rates and risk factors for nonadherence to the medical regimen after adult solid organ transplantation. Transplantation 83: 858-873.

13. Ichimaru N, Kakuta Y, Abe T, Okumi M, Imamura R, et al. (2008) Treatment adherence in renal transplant recipients: A questionnaire survey on immunosuppressants. Transplant Proc 40: 1362-1365.

14. Germani G, Lazzaro S, Gnoato F, Senzolo M, Borella V, et al. (2011) Nonadherent behaviors after solid organ transplantation. Transplant Proc 43: 318-323.

15. Weng FL, Chandwani S, Kurtyka KM, Zacker C, Chisholm-
Burns MA, et al. (2013) Prevalence and correlates of medication non-adherence among kidney transplant recipients more than 6 months post-transplant: A cross-sectional study. BMC Nephrol 14: 261.

16. Promraj $R$, Dumronggittigule $W$, Sirivatanauksorn $Y$, Ruenrom A, Tovikkai C, et al. (2016) Immunosuppressive medication adherence in liver transplant recipients. Transplantation Proc 48: 1198-1201.

17. Albekairy AM, Alkatheri AM, Jarab A, Khalidi N, Althiab K, et al. (2016) Adherence and treatment satisfaction in liver transplant recipients. Saudi J Gastroenterol 22: 127-132.

18. Muduma G, Shupo FC, Dam S, Hawken NA, Aballéa S, et al. (2016) Patient survey to identify reasons for non-adherence and elicitation of quality of life concepts associated with immunosuppressant therapy in kidney transplant recipients. Patient Prefer Adherence 10: 27-36.

19. Hamedan MS, Aliha JM (2014) Relationship between immunosuppressive medications adherence and quality of life and some patient factors in renal transplant patients in Iran. Glob J Health Sci 6: 205-212.

20. Özdemir Z, Talas MS (2017) Solid organ transplantasyonu sonrasi immünsupresif ilaç kullanimina uyum. Anadolu Hemşirelik ve Sağlik Bilimleri Dergisi 20: 304-310.

21. Griva K, Davenport A, Harrison M, Newman SP (2012) Non-adherence to immunosuppressive medications in kidney transplantation: Intent vs. forgetfulness and clinical markers of medication intake. Ann Behav Med 44: 85-93.

22. Scheel J, Reber S, Stoessel L, Waldmann E, Jank S, et al. (2017) Patient-reported non-adherence and immunosuppressant trough levels are associated with rejection after renal transplantation. BMC Nephrol 18: 107.

23. Burns MC, Pinsky B, Parker G, Johnson P, Arcona S, et al. (2012) Factors related to immunosuppressant medication adherence in renal transplant recipients. Clin Transplant 26: 706-713.

24. Gheith OA, El-Saadany SA, Abuo Donia SA, Salem YM (2008) Compliance with recommended life style behaviors in kidney transplant recipients: Does it matter in living donor kidney transplant? Iran J Kidney Dis 2: 218-226.

25. Russell C, Conn V, Ashbaugh C, Madsen R, Wakefield M, et al. (2011) Taking immunosuppressive medications effectively (TIMELink): A pilot randomized controlled trial in adult kidney transplant recipients. Clin Transplant 25: 864-870.

26. Burkhalter H, Wirz-Justice A, Cajochen C, Weaver TE, Steiger J, et al. (2014) Daytime sleepiness in renal transplant recipients is associated with immunosuppressive non-adherence: A cross-sectional, multi-center study. Clin Transplant 28: 58-66.

27. Morales JM, Varo E, La'zaro P (2012) Immunosuppressant treatment adherence, barriers to adherence and quality of life in renal and liver transplant recipients in Spain. Clin Transplant 26: 369-376. 